\title{
O FUTURO DOS JORNAIS DO INTERIOR
}

Beatriz Dornelles ${ }^{1}$

\section{RESUMO}

A partir de análise documental, bibliográfica e de conteúdo, realizada em 2011, este estudo apresenta dados sobre o investimento do setor empresarial no aprimoramento de produtos que explorem totalmente o poder da mídia impressa, incluindo a mídia digital. As tecnologias substitutivas estão sendo vistas pelos empresários de jornais interioranos brasileiros não como ameaça, mas como oportunidade, acompanhando a tendência dos atuais leitores de notícias: de cada dez leitores americanos, sete lêem notícias pela internet.

Palavras-chave: jornais do interior; noticiário local; comunidade; jornalismo on-line

\section{THE FUTURE OF NEWSPAPERS IN INNER CITIES}

\begin{abstract}
From document analysis, literature and content held in 2011, this study presents data on investment in the business sector to improve products that fully exploit the power of print media, including digital media. The alternative technologies are being seen by business newspaper Brazilian hinterland not as threat but as an opportunity, following the trend of current news readers: readers of every ten Americans, seven read news on-line.
\end{abstract}

Keywords: newspapers in the interior; local news; community; on-line journalism

\footnotetext{
${ }^{1}$ Professora Dra do PPGCom da PUCRS/Brasil - Bolsista Pós-doc/CNPq
} 


\section{O futuro dos jornais do interior}

O avanço das tecnologias utilizadas pelas empresas de comunicação, em especial, para o jornalismo e a publicidade, a criação de faculdades de Comunicação em várias cidades interioranas e a inclusão gradativa, mas ininterrupta, da sociedade brasileira à era digital, tem proporcionado a qualificação dos jornais do interior e, acreditamos, seu fortalecimento nos próximos dez anos.

A bibliografia especializada em "Jornalismo Interiorano", até onde pudemos pesquisar, é muito pequena e, muitas vezes, equivocada, pois ainda não credita aos jornais do interior a importância que eles de fato possuem para as suas comunidades, bem como não apresenta estudos aprofundados sobre a forma de produção dessas publicações. É bem mais fácil encontrar críticas ao jornalismo interiorano do que propostas para contornar problemas que afetam a qualidade do noticiário.

Nos países mais desenvolvidos, em particular os Estados Unidos, há relatos da crise pela qual vem passando a imprensa a partir do surgimento da Internet comercial e a queda significativa do número de leitores de jornais. Adolescentes e jovens adultos criaram o hábito de se informarem pela Internet no mundo inteiro. No Brasil a passagem do jornal impresso para o jornal on-line vem acontecendo de maneira gradativa e qualitativamente surpreendente.

Sabemos que a cada geração, o número de consumidores de jornais impressos diminui. Nos EUA, por exemplo, o fim dos jornais já é consenso entre os jornalistas e empresários da comunicação. Todavia, acreditamos que no Brasil precisaremos de mais tempo para que toda a imprensa funcione on-line. Aqui temos que resolver primeiro problemas com a qualidade do sinal da internet, disponibilizado à população. Por sinal, muito ruim se comparado aos Estados Unidos e países da Europa.

Com base numa rigorosa revisão do desempenho das empresas jornalísticas desde a década de 1970 e tomando como referência os conceitos sobre competitividade e estratégia empresarial de Michael Porter, um dos mais requisitados especialistas no assunto, Meyer (2007) elaborou dois cenários que balizarão a evolução dos jornais.

Segundo o pesquisador norte-americano, os jornais desfrutaram de um monopólio natural em seus respectivos mercados locais, em particular os pequenos e médios, e por eles a informação trafegava dos varejistas locais até seus clientes, proporcionando uma lucratividade superior à média. A diversificação das mídias mudou esse quadro de forma irreversível. A redução da circulação e o surgimento de alternativas para os anunciantes antecederam a 
internet. Entretanto, a principal resposta do setor de jornais à ameaça da tecnologia substituta tem sido reduzir custos e aumentar preços.

A manutenção dessa política, segundo Meyer, leva ao cenário do "pegue-o-dinheiro-ecorra, pela qual os controladores das empresas aumentam os preços e simultaneamente tentam manter sua rota de lucratividade com as técnicas usuais: diminuir o espaço editorial, cortar pessoal, reduzir a circulação em áreas remotas ou de baixa renda, adiar a manutenção e a melhoria na estrutura de capitais e manter baixos salários. Essa estratégia pode funcionar, mas Meyer acredita que ela não se sustentará.

O segundo cenário supõe que os controladores atuais das empresas jornalísticas ou seus sucessores aceitarão a realidade da nova competição, investirão no aprimoramento de produtos que explorem totalmente o poder da mídia impressa, incluindo a mídia digital. Adotar essa estratégia supõe ver as tecnologias substitutivas não como ameaça, mas como oportunidade. Este quadro é o que já conseguimos vislumbrar para os jornais interioranos brasileiros.

Para que essa estratégia seja bem-sucedida, contudo, Meyer (Ibid.) sustenta que o jornalismo como negócio não deve ser entendido como a intermediação entre leitores e anunciantes, mas como a produção de influência. Isso o leva a sustentar que a melhor maneira de garantir o futuro dos jornais seria conservar sua influência e pagar os custos das experiências radicais. Elas são necessárias para aprender quais novas formas de mídia serão viáveis num mercado muito mais complexo que no passado, no qual a informação em si não é mais escassa e, portanto, tem menos valor. O bem cobiçado não é nem percentagem da circulação, nem a percentagem de leitores, mas a percentagem da quantidade finita da atenção do público.

Encarada por esse ângulo, nos últimos anos e atualmente a principal questão estratégica para os jornais, segundo o pesquisador, passa a ser "descobrir e compreender as populações segmentadas onde há maior viabilidade de conquistar essa confiança e exercer influência".

Dentro deste contexto, observamos que muitos empresários brasileiros mudaram de atitude em relação aos jornais e buscaram novidades para o mercado em todos os aspectos, destacando-se uma nova visão de jornalismo participativo, através da internet, mudanças na distribuição do jornal, no seu aspecto gráfico, em estratégias publicitárias, na busca de leitores jovens, na formação continuada dos jornalistas e na execução de programas que inserem o jornal na sala de aula, visando contribuir para formação dos estudantes brasileiros. 
Dados da mídia norte-americana, divulgados pela internet, relativos há cinco anos, mostram que de cada dez leitores americanos, sete lêem notícias pela internet. Isso fez com que os grupos de comunicação dos EUA investissem nessa nova mídia. É isso, também, que podemos verificar no Brasil, em especial, nas cidades do interior, já que este estudo trata deste segmento da imprensa.

Até o momento, podemos observar a utilização cada vez maior da internet pelos empresários da comunicação do interior dos Estados, tanto os mais antigos quanto jovens que se lançam no mercado de jornais através da internet, acompanhando a tendência dos atuais leitores de notícia.

\section{Localismo}

Historicamente, os jornais do interior sempre priorizaram o "localismo", muitas vezes não obtendo o resultado esperado em termos de popularidade e comercialização do produto. Agora, no entanto, vislumbras-se a possibilidade de colheita farta desta opção jornalística, que muitas vezes foi criticada pelos profissionais da área por entenderem muito restrita.

Pode-se observar desde já que o jornalismo on-line favoreceu o localismo, pois ampliou a demanda por informações locais de qualidade, já que questões de âmbito estadual, nacional e, principalmente, internacional, são fartamente exploradas pelos portais, sites e blogs.

A tendência do "localismo" é tão forte que parte da imprensa está conduzindo os jornais de grandes metrópoles a também ampliarem a divulgação de fatos locais, até então ocupando um espaço periférico na pauta das grandes redações jornalísticas.

Fortaleceu-se, assim, a cobertura dos bairros, no que pese ainda ser deficiente, pois continuam prevalecendo os critérios de noticiabilidade, utilizados antes do advento da internet, tais como: raridade, polêmicas, crimes hediondos, economia das elites, destaque aos famosos.

Na realidade, o território de pertença e de identidade, ao qual a informação local parece estar ancorada, pode por si só condicionar as formas de divulgação da imprensa local, reduzindo-as a uma escala mais restrita e comunitária. No entanto, isto não significa necessariamente um limite às audiências.

A circulação impressa dos jornais do interior, estrategicamente localizada em determinada região, por suas características restringe, naturalmente, o seu âmbito de ação, 
pois está irremediavelmente amarrada a questões como o espaço geográfico, também o lugar de produção e de cobertura dos acontecimentos; ao espaço de circulação do impresso; aos conteúdos locais; à informação disponível; ao interesse do público local e, especialmente, à economia da região por onde circula. Já na internet estes problemas serão sanados.

Desta forma, é determinante o papel que a geografia desempenha na definição de informação local. Ela pode ser entendida mais pelo espaço geográfico do que pelas características de seu conteúdo. Já o jornalismo do interior, além da questão geográfica, pode ser reconhecido por outras características próprias por serem do interior.

Assim, a comunicação local diz respeito à maioria das pessoas e membros integrados em determinado sistema local, ocorrendo de forma constante. Entende-se por "local" a informação relativa a um bairro urbano ou a uma pequena comunidade ou a cidades de pequeno porte.

O próprio jornal local deve ainda refletir a mesma delimitação geográfica, na forma como organiza as informações em cada edição, podendo recorrer mesmo a páginas especiais, destinadas às diferentes situações de cobertura. Ele deve ser constituído por notícias que dizem respeito a uma área geográfica relativamente restrita.

Essa é a fórmula, por exemplo, que seguem os atuais jornais interioranos do Rio Grande do Sul, Estado que tradicionalmente apresenta um jornalismo de ponta, ousado, inovador e independente. Eles deixam para a imprensa das grandes cidades e para internet a divulgação de fatos de âmbito nacional ou internacional, priorizando os acontecimentos e personalidades locais. O que ainda falta aos jornais interioranos é a repercussão de acontecimentos nacionais ou internacionais junto a seus públicos, considerando as consequências sobre a população local.

Estudo publicado na Espanha por Mercadé (1997) apresenta para a discussão do jornalismo local outros elementos particularmente relevantes. $\mathrm{Na}$ sua proposta de classificação da imprensa regional, para além do território, refere-se a outros critérios determinantes para a delimitação e formação dos conteúdos da imprensa local e regional.

Segundo o pesquisador, dever-se-ia ter em conta questões como a sede territorial da publicação; o seu âmbito de difusão e cobertura; a vocação e intencionalidade da publicação; o tratamento dado aos conteúdos; a percepção do jornal sobre o leitor; e a relação com as fontes de informação institucionais, no que concordamos como relevante para a imprensa interiorana brasileira. 
Para Mercadé (Ibid.), a imprensa regional tem por área privilegiada de difusão a região ou a cidade na qual se situa também a sua sede editorial. A vocação, a intencionalidade, os conteúdos e a percepção sobre o leitor são determinados pelo contexto local ou regional, sendo também as relações com as instituições e organismos locais e regionais mais diretas, de caráter permanente e num grau maior de intensidade, comparativamente aos jornais que se encontram administrativa, política e economicamente a um nível de desenvolvimento maior. Os itens apontados por Mercadé são mais completos, pois valorizam outros aspectos, que não apenas os relacionados à localização geográfica dos jornais.

Essa ancoragem da imprensa local sobre o território/conteúdo, salientada acima, parece evidenciar que a imprensa local constrói a sua razão de ser, a sua especificidade e a sua força entre a sua localização territorial e a territorialização dos seus conteúdos.

$\mathrm{Na}$ Europa, há registro de que aumentou o interesse de grandes grupos de comunicação em produtos de origem local e regional, por tratar-se de um campo de mercado em expansão. Segundo Camponez (2002) "o mercado da proximidade, à medida que a concorrência entre os grandes títulos nacionais se acentua, surge como uma alternativa, num contexto mediático cada vez mais exigente em termos financeiros e onde só os grandes parecem ter lugar" (Ibid. p. 115).

O mesmo autor destaca o reconhecimento da importância da informação local pelos políticos em decorrência da valorização de gestões e administrações públicas a serem exercidas localmente, quer pela via da regionalização, quer pela via da descentralização. Afirma Camponez (Ibidem): “A complexificação da administração pública vai acabar por exigir uma maior localização das decisões e, consequentemente, reforçar o papel da informação local.

$\mathrm{Na}$ União Europeia a informação local aparece como uma clara alternativa de disseminação da informação. Políticos daquela região apontam os meios de comunicação social regionais e locais como imprescindíveis entre a superestrutura da União Europeia e o dia-a-dia dos cidadãos. Em entrevista à imprensa regional portuguesa, na cidade do Porto, Helena Vaz da Silva, ex-deputada socialista do Mercado Comum Europeu, afirmou que são os jornais locais e regionais que podem traduzir em linguagem concreta as normas e legislação europeias, "assim como são eles que podem fazer chegar às instituições europeias os anseios e as dificuldades de cada região"2.

\footnotetext{
${ }^{2}$ Citação retirada do jornal Diário Regional de Leiria, de 13 de outubro de 1998, p. 9, apud Camponez, 2002, p. 115.
} 
Segundo a deputada portuguesa, "a imprensa e a rádio regional e local, além de fornecerem informação credível, podem e devem funcionar como referência e motor de mudança na sociedade em que se inserem”. Como se verifica, o papel estratégico da proximidade dos media locais e regionais face aos seus leitores é evidenciado.

A importância da proximidade, um dos principais elementos da notícia e, no meu entender, o mais importante para imprensa interiorana, já vem sendo valorizada há décadas pelos jornais do interior do Brasil.

Teun van Dijk ${ }^{3}$, quando trata dos valores-notícia, refere que a proximidade local e ideológica é, de alguma forma, transversal a todos os restantes valores. É a proximidade que permite ao jornalismo perceber os contextos que determinam os valores-notícia e, a partir daí, organizar os restantes elementos valorativos, como a novidade, a atualidade, a relevância, a consonância, o desvio e a negatividade.

O autor inclui ainda como valor-notícia a "pressuposição", que nos remete particularmente para o conhecimento prévio dos contextos e das crenças sociais de onde emerge a notícia. Segundo ele, "a proximidade ideológica resulta dos critérios gerais de consonância".

A proximidade local inclui a pressuposição de conhecimentos adquiridos, bem como o da relevância. Sabemos mais sobre o nosso próprio bairro, cidade, país, continente, em parte pela experiência direta e pelas comunicações informais das experiências de outros que conhecemos $^{4}$. Por isso, os acontecimentos que nos são mais próximos são melhor compreendidos, pois também proporcionam melhores temas de histórias para comentar no quotidiano.

\section{Funções da Imprensa do Interior}

A particularidade da imprensa local/regional funda-se no fato de se dirigir ao indivíduo, enquanto sujeito integrado e participante numa comunidade geográfica delimitada, da qual é possível conhecer as características: mentalidades, hábitos, modos de viver, níveis de vida, preocupações culturais e sociais dominantes etc ${ }^{5}$.

\footnotetext{
${ }^{3}$ Teun van DIJK, La Noticia Como Discurso - Comprensión, estrutura y producción de la Información, Barcelona, Buenos Aires, México, Paidós, col. Paidós Comunicación, 41, 1996, p. 173-181.

${ }^{4}$ Lorenzo GOMIS. Teoria del Periodismo - Como se forma el presente. Barcelona, Buenos Aires, México, Paidós, col. Paidós Comunicación, 44, 1997.

${ }^{5}$ M. MATHIEN, La Presse Quotidienne Régionale, op. cit., 2004, p. 43.
} 
Assim, segundo Mathien (2004, p.43), a imprensa regional desempenha um conjunto de funções entre as quais as mais determinantes são:

- Servir de elo da comunidade a que se dirige;

- Constituir-se como complemento à experiência quotidiana dos seus leitores, completando-a através da informação disponível, quer sobre a realidade mais próxima, quer sobre os acontecimentos mais distantes;

- Reduzir a incerteza do ambiente que rodeia o leitor, tentando responder às questões banais acerca das novidades e da atualidade;

- Funcionar também como enciclopédia dos conhecimentos vulgarizados, a partir da qual o leitor, bem ou mal, adquire e alarga a sua cultura, acerca dos conhecimentos mais diversificados e superficiais;

- Servir como um importante banco de dados sobre a região de influência, uma tarefa facilitada agora pelo desenvolvimento dos sistemas informáticos e das redes.

Para além disso, acrescenta Mathien, a imprensa regional detém a vantagem de poder mobilizar arquivos e organizar estes serviços de forma polivalente, centralizada e dispondo de alguma facilidade em assegurar uma constante atualização, e, por último, a imprensa regional desempenha ainda uma função de recreio e de psicoterapia social.

Esta ligação à comunidade de leitores está bem patente na ancoragem do jornal local a um determinado território, cuja pequenez de fronteiras transforma radicalmente o conceito de proximidade jornalística, também presente nos jornais de expansão nacional. A tradução do jornalismo interiorano encontra expressão na grande penetração do jornal nas suas áreas de influência, que são também as áreas da sua audiência. Ou seja, aquilo que os jornais de expansão nacional tendem a ganhar em dimensão do mercado, perdem-no em termos de penetração.

Em Portugal, por exemplo, o Estudo de Notoriedade e Audiência de Imprensa Regional, de setembro de 1992, efetuado pela empresa Markteste e encomendado pela Associação Portuguesa de Controle de Tiragens (apud CAMPONEZ, 2002, p. 124), mostra que os jornais regionais e locais de Portugal ocupam um papel dominante nos índices de leitura da imprensa, superando de longe os semanários e diários nacionais de maior audiência. O mesmo acontece no Rio Grande do Sul (Brasil), conforme estudo realizado por mim entre 
2000 e 2005, em sequência ao estudo realizado durante doutoramento ${ }^{6}$. Esta característica confere ao jornalismo dos pequenos acontecimentos um estatuto elevado no que se refere à informação local e, consequentemente, à formação do espaço público local de opinião.

Uma constatação que é ainda reforçada pelo estudo realizado em seis países europeus pela Carat, uma empresa especializada na compra de espaço publicitário, e que, por exemplo, no caso da imprensa regional diária alemã, detectou taxas de penetração de 230,4 por mil habitantes $^{7}$. O que se destaca, então, na imprensa local ou do interior é o compromisso editorial e comunicacional com a comunidade.

Assim, podemos sustentar que a imprensa do interior, caracterizada especialmente pelo localismo, funciona em um espaço mais ou menos limitado, por seleção do tipo de informação, por identificação com o público, pelo partilhamento dos fatos, dos interesse, das necessidades, das reivendicações políticas etc. O jornal, então, deve servir aos interesses nobres da comunidade a que deve a sua existência e o seu sustento.

\section{Levantamento Dos Jornais On-Line}

Para este estudo, ainda em andamento, partimos de um levantamento dos jornais do Rio Grande do Sul que circulam na internet ${ }^{8}$. Encontramos 115 jornais on-line e vários outros sendo implementados. As cidades-sede desses jornais, do ponto de vista da população, variam de 6 mil (como Passo do Sobrado) a 435 mil (caso de Caxias do Sul) habitantes.

Até o momento não encontramos nenhum indício de similaridade entre os jornais que já circulam on-line e os que ainda permanecem na condição de jornais impressos. Há jornais on-line em cidades de diferentes economias e populações, desde às fracas até às muito fortes.

Também não encontramos as razões que determinam a escolha de jornais on-line em portais, sites ou blogs. Alguns têm atualização diária, outros semanal, outros quinzenal e até mensal. E há ainda um grupo de jornais com atualização em tempo real e interligado às redes sociais.

Sobre os recursos utilizados, encontramos de tudo. Há jornais multimídia, com vídeos, recursos gráficos, fotografias e áudio. Outros seguem a fórmula gráfica: textos e fotos.

\footnotetext{
${ }^{6}$ Os dados levantados no estudo citado estão sendo apresentados em artigos científicos, publicados em diferentes revistas científicas. Mais detalhes da pesquisa de doutoramento ver em: DORNELLES, B. Jornalismo "Comunitário" em Cidades do Interior. Ed. Sagra Luzzatto, 2004.

${ }^{7}$ Lorenzo GOMIS. Teoria del Periodismo - Como se forma el presente. Barcelona, Buenos Aires, México, Paidós, col. Paidós Comunicación, 44, 1997.

${ }^{8}$ A identificação de jornais on-line foi finalizada em 3 de maio de 2011, com participação da bolsista PIBIC/PUCRS Jeniffer Severo do Curso de Jornalismo da Famecos.
} 
Outros apresentam impressionante qualidade no layout do site; outros ainda deixam a desejar em termos de qualidade.

O que parece ser um consenso entre os produtores de jornais é a necessidade de manter um canal direto de contato e participação do povo na produção da notícia. Com certeza, este item irá provocar (se é que já não está provocando) mudanças na pauta dos jornais e nos critérios de noticiabilidade utilizados pelos jornalistas.

Sobre o produto propriamente dito, há várias situações: jornais exclusivamente produzidos para internet; jornais que disponibilizam a versão impressa, sem acréscimo de nenhum outro recurso gráfico; jornais com atualização em tempo real via twitter e G1; jornais com atualizações diárias através de outros sites; jornais contendo vídeos das notícias, disponibilizados através do Yutube; jornais interligados a rádios digitais; jornais com diversas formas de interatividade e jornais com espaço de participação do público destacado.

Todos os modelos listados não apresentam similaridade aparente. Qualquer um deles pode representar uma pequena cidade, ou grande; uma economia forte, ou fraca; a presença ou não de profissionais de comunicação; jornais que pagam bons e baixos salários; jornais com grandes equipes e com pequenas. Nenhum destes itens caracteriza este ou aquele tipo de jornal on-line.

\section{Conteúdo}

A pesquisa sobre a passagem dos jornais do interior para internet está quase pronta, mas podemos adiantar alguns requisitos em relação ao conteúdo das notícias. Até momento é possível verificar que a "proximidade" é ainda a prioridade do noticiário do interior. Os acontecimentos locais, os problemas que afetam as cidades, as personalidades locais, a economia do município, os representantes políticos locais, os crimes que ocorrem na cidade e os seus atletas e artistas ainda prevalecem no noticiário do interior, o que está rigorosamente correto do ponto de vista de viabilização do produto.

O que ainda não pudemos observar é a adoção de um jornalismo mais combativo, investigativo, denunciador das "falcatruas" locais. Os jornais impressos, historicamente, por várias razões, não se encontram em posição de enfrentarem os políticos e empresários de municípios de pequeno porte. Acreditamos, no entanto, que esta realidade será alterada quando o jornalismo estiver sendo produzido para portais e sites da internet. 
Os leitores terão uma forte ferramenta para exercerem pressão sobre os jornais de maneira que eles se sintam respaldados pela comunidade para enfrentarem os "poderosos". Esta mudança, no entanto, ainda não está acontecendo. E para que aconteça será necessária uma campanha de conscientização dos internautas para que entendam a força que possuem no sentido de fiscalizar a mídia local e obrigá-la a apresentar um jornalismo independente e de qualidade.

Na maioria dos casos, pelo menos no Rio Grande do Sul, esta fiscalização da comunidade representa muito mais um apoio aos profissionais da imprensa para que atuem com liberdade e imparcialidade, apoio este que não é visível em termos de assinantes de jornais do interior.

Outra tendência verificada a partir da pesquisa foi a possibilidade dos portais das prefeituras, que apresentam notícias sobre a administração da cidade, com atualização diária, tornarem-se concorrentes de alguns jornais locais. Isto porque muitos deles ainda são bastante precários em termos de cobertura local, qualidade de texto e apresentação gráfica. Não se pode esquecer que as prefeituras possuem recursos financeiros e de pessoal para realizarem este trabalho, enquanto muitos jornais não possuem condições financeiras para contratar profissionais qualificadas. Se a comercialização dos jornais na internet não sofrer um impulso, a tendência será o fechamento desses periódicos.

\section{Características dos jornais do interior impressos}

Nossos estudos em torno dos jornais interioranos impressos revelam que os diários, trissemanários e bissemanários, em cidades com até 300 mil habitantes (ressalvando-se algumas exceções), priorizam a divulgação de fatos locais, de interesse da comunidade por onde circula, tendo como fonte os moradores da região, e com poucas declarações de autoridades estaduais ou federais.

A atuação das associações e organizações não-governamentais tem destaque privilegiado nestes jornais, bem como o cotidiano das escolas da cidade, dos clubes, do policiamento, do movimento do comércio, dos movimentos culturais e da atuação de cidadãos da cidade, que se destacam por ações sociais, comunitárias, educativas, artísticas, culturais, e não só pela escala social que representam.

A quase totalidade das notícias publicadas pelos jornais do interior (muitas vezes $100 \%$ das edições) não é contemplada pela grande mídia (jornais de grandes empresas de 
comunicação, emissoras de rádios e televisão). Além disso, grande número de produtores dos jornais do interior, além de administrarem seus negócios visando lucro, objetiva contribuir para educação informal dos leitores e proporcionar a prática da cidadania.

Alguns jornais atuam com maior pressão ao poder executivo. Insistem com as prefeituras para que apresentem soluções para problemas da comunidade, através da exposição pública e recorrente do fato. Isto equivale a dizer que os jornais não trabalham apenas com o objetivo de "informar", como a grande maioria da imprensa diária se caracteriza. Esta postura dos jornais é explícita e defendida pelos mesmos como politicamente correta, não havendo a preocupação de serem taxados de "jornalistas parciais, subjetivos ou engajados em causas comunitárias". É isso mesmo que um grupo deles é, pois opta pela defesa dos problemas e carências de determinados segmentos sociais ou de toda uma comunidade.

Todavia, a grande maioria dos jornais que circulam em cidades do interior com mais de 100 mil habitantes, geralmente com periodicidade diária, salvo raras exceções, repetem as mesmas práticas de produção da notícia dos grandes jornais. E copiam também os projetos gráficos dos mesmos.

Outra característica diferenciada de alguns jornais do interior é a criação do Conselho do Leitor, integrado por cidadãos representativos de diferentes segmentos normalmente foco do noticiário do jornal: saúde, educação, habitação, igrejas, consumidores, associações de moradores, de lojistas, de trabalhadores, sindicatos, segurança pública, entre outros. Os membros do Conselho são responsáveis por analisar e discutir o conteúdo do jornal, fazer sugestões, criticar e propor mudanças.

As características dos jornais do interior são tantas que é possível identificarmos vários tipos no Brasil, entre centenas deles. Destaco, primeiramente, aquele que pertence a uma empresa jornalística, que visa lucro, portanto, com interesses mercadológicos, comercializa espaço publicitário, dá cobertura aos acontecimentos locais, com a abordagem de assuntos diretamente sintonizados com a realidade local, que em geral não têm espaço na grande mídia. Esses podem ser identificados como um reprodutor da lógica dos grandes meios de comunicação, principalmente no que se refere ao sistema de gestão e aos interesses em jogo. Explora o local enquanto nicho de mercado, ou seja, os temas e as problemáticas específicas da localidade interessam enquanto estratégias para se conseguir aumentar a credibilidade e a audiência, e conseqüentemente obter retorno financeiro. 
Em segundo lugar, temos os jornais com algumas características citadas acima, mas com interesses diferenciados, como contribuir para a ampliação da cidadania e favorecer a participação popular; ocupando-se com questões relativas às desigualdades e movimentos sociais. Às vezes desempenham papéis que extrapolam as funções tradicionais de um jornal, colocando-se como agente de cobrança e no papel de protagonista na solução de um problema social.

O primeiro tipo é mais apropriado para enquadrarmos um segmento de jornais do interior; o segundo, para os jornais comunitários, sem fins lucrativos. Um terceiro tipo caracteriza-se pelo comprometimento político com o staff governamental ou legislativo e/ou com as forças do poder econômico da região, o que fica visível na leitura dos conteúdos dos jornais. Matérias jornalísticas favoráveis a algumas correntes políticas, principalmente daquelas que estejam no exercício do poder; a omissão do jornal em relação a desmandos do Executivo, de práticas injustas, de negligência na administração pública e notícias contendo apenas um lado da história é corrente em jornais dessa categoria. Também verificamos a presença de matérias pagas, mascaradas como notícia selecionada pelo jornal ${ }^{9}$.

Em nosso estudo sobre a imprensa interiorana encontramos, ainda hoje, poucas matérias contendo críticas, denúncias ou cobrança do poder executivo local, comportamento que revela a falta de independência e autonomia desses jornais em nome da sobrevivência. Todavia, a maioria encontra um jeito moderado de cobrar ações pró-comunidade. Fazem as matérias em tom de advertência do problema ou de registro das reivindicações da comunidade. Acreditamos que a prática jornalística responsável, comprometida com as necessidades sociais, de alguma forma representa a maioria dos jornais do interior que se apresentam na internet.

Destacamos, ainda, outras características que podem ser identificadas em alguns jornais interioranos: divulgar assuntos, específicos das comunidades, de movimentos coletivos e de segmentos populacionais ou do interesse público, que normalmente não encontram espaço na mídia convencional; ter como principal motivação o desenvolvimento comunitário como forma de ampliar o exercício dos direitos e deveres de cidadania; os conteúdos dizem respeito às necessidade, problemáticas, artes, cultura e outros temas de interesse local, como por exemplo: notícias das associações de moradores de bairros, matérias de saúde com enfoque preventivo, matérias educativas; campanhas para educação ao trânsito

\footnotetext{
${ }^{9}$ Os jornais deveriam registrar no início ou no fim da matéria que trata-se de texto pago pela pessoa ou instituição responsável pelo texto.
} 
e proteção do meio ambiente; reivindicações de serviços públicos de uso coletivo e outras informações de utilidade pública; contribuir para a conscientização e organização de segmentos menos favorecidos da população, visando superar as desigualdades e instaurar mais justiça social. Ao final, a estratégia principal é interagir com a comunidade local, enfocando temas específicos do lugar.

Como destacou Peruzzo (2002), não basta falar de coisas do lugar para que haja identificação com a comunidade. O que mais importa são as identidades, o vínculo e a inserção como parte de um processo comunitário mais amplo, ou seja, o compromisso com a realidade concreta de cada lugar. E se o objetivo do jornal for a prática do jornalismo comunitário, ele terá que ter por objetivo a mobilização social, o engajamento em lutas da comunidade, espaços para reflexão, além de outras características comunitárias.

\section{Referências Bibliográficas}

ANUÁRIO Unesco/UmesP de COMUNiCAÇÃo Regional. Ano 6, nº 6, jan-dez. São Bernardo do Campo: Umesp/SP, 2002.

AREAL, M. F. El público en los medios locales de comunicación. In: $A A V V$, Estudos de Periodística V - Número especial dedicado ao jornalismo local, 1997.

BELTRÁN, Luiz Ramiro. Adeus a Aristóteles: comunicação horizontal. Comunicação \& Sociedade, São Bernardo do Campo: IMS, ano III, nº 6, set. 1981.

BIZ, Osvaldo. A década de 90 no Brasil. Anotações realizadas para disciplina Realidade Brasileira, ministrada na Famecos/PUCRS, 2005.

BOND, Fraser. Introdución al Periodismo. México, Editora Americana, 1965, p. 100.

BRUM, Argemiro Jacob. O desenvolvimento econômico brasileiro. Petrópolis: Vozes, 1996.

CALlADO, Ana Arruda \& DUQUE ESTRADA, Maria Ignez. Como se faz um jornal comunitário. Petrópolis: Vozes/Ibase, 1985.

CAMPONEZ, Carlos. Jornalismo de Proximidade. Ed. Coimbra, 2002.

CAPARELLI, Sérgio. Imprensa alternativa. In: Comunicação de massa sem massa. $3^{\mathrm{a}}$ ed. São Paulo: Summus, 1986.

CELADEC. Jornalismo popular. São Paulo, Paulinas, 1984. 
DIJK, Teun van. La Noticia Como Discurso - Comprensión, estrutura y producción de la Información, Barcelona, Buenos Aires, México, Paidós, col. Paidós Comunicación, 41, 1996.

DORNELLES, Beatriz. Jornalismo "comunitário" em cidades do interior. Porto Alegre: Sagra Luzzatto, 2004.

DRAGON, Alfonso Gumucio. Haciendo Olas - Historias de comunicación participativa para el cambio social. The Rockefeller Foundation, 2001.

FERRARETTO, Elisa Kopplin. Do universo técnico-científico ao mundo do senso comum: estratégias comunicativas e representações na cobertura sobre saúde do Diário Gaúcho. Porto Alegre: UFRGS, 2006. (Dissertação de Mestrado - Faculdade de Biblioteconomia e Comunicação).

FESTA, Regina. Comunicação popular e alternativa. A realidade e as utopias. São Bernardo do Campo, IMS, 1984.

GOMES, Pedro Gilberto. O Jornalismo Alternativo no projeto popular. Paulinas, São Paulo, 1990.

GOMIS, Lorenzo. Teoria del Periodismo - Como se forma el presente. Barcelona, Buenos Aires, México, Paidós, col. Paidós Comunicación, 44, 1997.

KAPLUN, Mario. Hacia nuevas estrategias de comunicación en la educación de adultos. Santiago, OREAL/ Unesco, 1983.

LINS DA SILVA, Carlos Eduardo. Jornalismo popular no Rio Grande do Norte. Comunicação \& Sociedade, São Bernardo do Campo, IMS, set. 1981 apud GOMES, Pedro Gilberto. In: O Jornalismo Alternativo no projeto popular. São Paulo: Paulinas, 1990.

MARQUES DE MELO, José. Imprensa comunitária no Brasil. Comunicação \& Sociedade, Cortez e Moraes, 2, dez. 1979 apud GOMES, Pedro Gilberto. In: O Jornalismo Alternativo no projeto popular. Paulinas, São Paulo, 1990.

A opinião no jornalismo brasileiro. Petrópolis, Vozes, 1985.

Comunicação comunitária. A imprensa comunitária no Brasil. In: Comunicação \& Libertação. Petrópolis, Vozes, 1981 apud GOMES, Pedro Gilberto. In: O Jornalismo Alternativo no projeto popular. Paulinas, São Paulo, 1990.

A emergência de um novo jornalismo católico. In: Comunicação: teoria e política. São Paulo: Summus, 1985.

Comunicação \& libertação. Petrópolis: Vozes, 1981.

Para uma leitura crítica da comunicação. São Paulo: Paulinas, 1985.

MERCADÉ, J. M. La fuerza del periodismo local em la era de la globalización electrónica. Pontevedra, 1992. 
M. MATHIEN, La Presse Quotidienne Régionale, (s.ed.), 2004.

MOMESSO, Luiz Anastácio. A emergente imprensa na periferia de São Paulo. Comunicação \& Sociedade, Cortez e Moraes, mar. 1981.

PERUZZO, Cicília. Globalização da mídia e a comunicação comunitária. Revista Interface. Vitória: UFES, março de 1996.

Comunicação nos movimentos populares - a participação na construção da cidadania. Petrópolis: Vozes, 1998a.

Mídia comunitária. Revista Comunicação e Sociedade, $n^{0}$ 32. São Bernardo do Campo: UMESP, 1998 b.

- Mídia local e suas interfaces com a mídia comunitária. In: Anuário UNESCO/UMESP de Comunicação Regional, Ano 6, n. 6, jan-dez, São Bernardo do Campo: UMESP/SP, 2002.

PINHEIRO, Flávio. Jornalismo Alternativo; Alternativa do Jornalismo. In: Memórias II Gamacom - Ideologia \& Poder da Comunicação Alternativa, Universidade Gama Filho, 1996.

PUCHEU, René. L’information locale. In: Press Actualité, nº 79, janeiro, 1973,

RAIMUNDO, Orlando. A linguagem dos jornalistas - Manual de escrita jornalística. Ericeira, O Acontecimento, s. d.

SATO, Nelson Kengo. Número de Jornalistas no Brasil - 1986 a 2002. Disponível em: <www.fenaj.org.br/mobisa/numero_jornalistas.doc>. Acesso em: 11/01/2006, às 16 horas.

TRAMONTE, Cristiana e SOUZA, Marcio Vieira. A comunicação na aldeia global. Petrópolis: Vozes, 2005. 